\title{
Research on the knowledge-based comprehensive decision support system for human resource management in SaaS mode
}

\author{
Liangtie Dai Qiongyu Zhou \\ Management School \\ Ji Nan University \\ Guangzhou city of Guangdong Province, China \\ dailiangtie@163.com
}

\begin{abstract}
This research puts forward the structure model of knowledge-based decision support system (DSS), which includes knowledge base, reasoning machine, model base, method base and database. With the six-layer structure of data management process, the knowledge-based DSS adopts distributed resource organization and task allocation strategy for cloud computing to optimize data processing. Besides, we design development tools of human resource management (HRM) expert system for knowledge base and reasoning machine and construct a comprehensive DSS for HRM, which includes knowledge base, model base, method base and various management modules. The applications in enterprises, business and education are also shown here.
\end{abstract}

Key words-knowledge, SaaS model, expert system, human resource management, decision support system

\section{INTRODUCTION}

Since the proposing of DSS in the 1970s, extensive research has been done to analyze, design, develop, realize and evaluate it, which makes it grow rapidly. Nowadays DSS has been used in many fields, such as finance, insurance, retail, telecommunications and government to provide good decision supports. In our country, some researchers has focused on the applications of DSS in specific HRM domain, such as supply and demand dynamics forecast DSS and file information DSS, instead of the comprehensive domains of HRM. On the basis of previous research on DSS, this research aims to build a knowledge-based comprehensive DSS for HRM in the SaaS mode, which can help enterprises to solve various decision and consultation problems they are facing more effectively and comprehensively.

\section{CLOUd COMPUTING MODEL FOR HRM IN THE SAAS MODE}

SaaS (Software as a service) is a main service mode of Cloud Computing, which means that developers develop computer software of $\mathrm{B} / \mathrm{S}$ structure and place it on the servers so that users in different regions can make corresponding operations on the modules of HRM with their own computers. For example, users can query, add and modify all types of related information on demand and preserve the processing results into servers' databases

Practical activities have proved that HRM system is versatile in a certain extent. With the building of the knowledge-based comprehensive DSS for HRM in the
SaaS mode, enterprises and institutions could receive needed HRM services in the "cloud" while paying little fee and becoming more efficient and normative .

SaaS mode usually depend on the SOA architecture and web Service technology. SOA means service-oriented architecture, on the basis of which we can develop many web services of HRM, while these service modules and the software and hardware elements they are based on, together constitute the "cloud" of HRM. The structure is shown in the figure 1 :

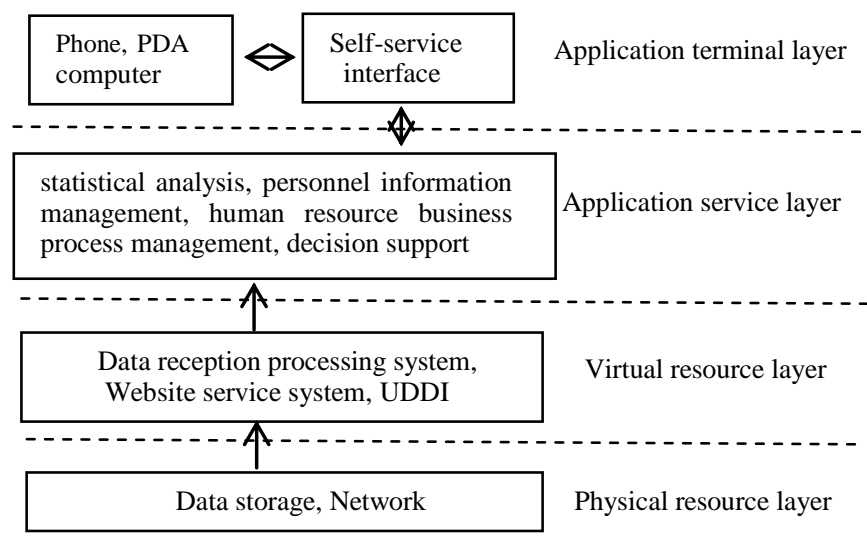

Fig. 1.the cloud-based HRM system

Physical resource layer contains data storage and application, web servers, network transmission or data transmitting and receiving devices. These devices may be located in different places through private or public network, but with the same communication mechanism to ensure the synchronization of data updating.

Virtual resource layer contains software for basic data management and information processing, which is used for underlying information processing, whose stability determines the validity of all applications services on the application service layer. Application service layer provides various types of application services for comprehensive HRM, which refers to the software that users directly access to and use. These applications are called and used through a browser.

Application terminal layer is a scalable platform which integrates kinds of application services and has the function of dynamic integration of various types of access interface. The platform can be accessed and applied by connecting services terminals. Users send a call request by the terminals, then the sever calls up the appropriate 
access portal interfaces while receiving the request, and then users make corresponding operation according to the interface requirements.

\section{THE BUILDING OF KNOWLEDGE-BASED DSS FOR HRM IN THE SAAS MODE}

\section{A. DSS structure based on X libraries}

In 1980, Sprague proposed DSS structure based on the two bases, the model base and database.

It contains three components: data subsystems, model subsystems and human-computer interaction system. Among them, data subsystem is used to store and manage data used in DSS, and realizes the mutual transformation between different data sources; Model subsystems store the scheduled standard model and support the analysis, management and calculation of models; Human-computer interaction subsystem is an interface between the DSS and users, which is responsible for receiving requests and providing users with auxiliary decision-making results.

Sprague's two-base structure determines the basic functions and structure of DSS, which was followed by structure pattern of three, four, five, six and seven database. Based on the two-base mode, the three-base structure pattern adds knowledge base to improve its ability of qualitative analysis; Four-base pattern adds method base to realize the separation of models and methods; Five-base pattern adds text database to provide descriptive information of decision problems, etc.

\section{B. DSS structure based on knowledge}

In 1981, American researcher, Bonczek, proposed knowledge-based DSS of three-base structure pattern, as shown in Fig.2:

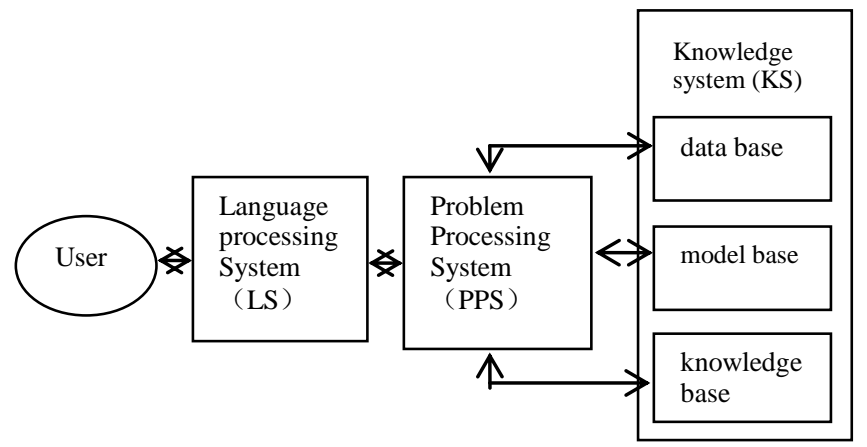

Fig. 2.Bonczek's knowledge-based DSS architecture

The system structure views data, models and methods as unified knowledge. Containing KS, Bonczek's DSS means that the artificial intelligence technology is applied to DSS. Thus, the proposition of knowledge-based DSS is viewed as the symbol of appearance of the Intelligent Decision Support System (IDSS).

\section{The building of IDSS}

On the basis of Bonczek's DSS structure, our research put forward the IDSS structure, as shown in Fig.3:

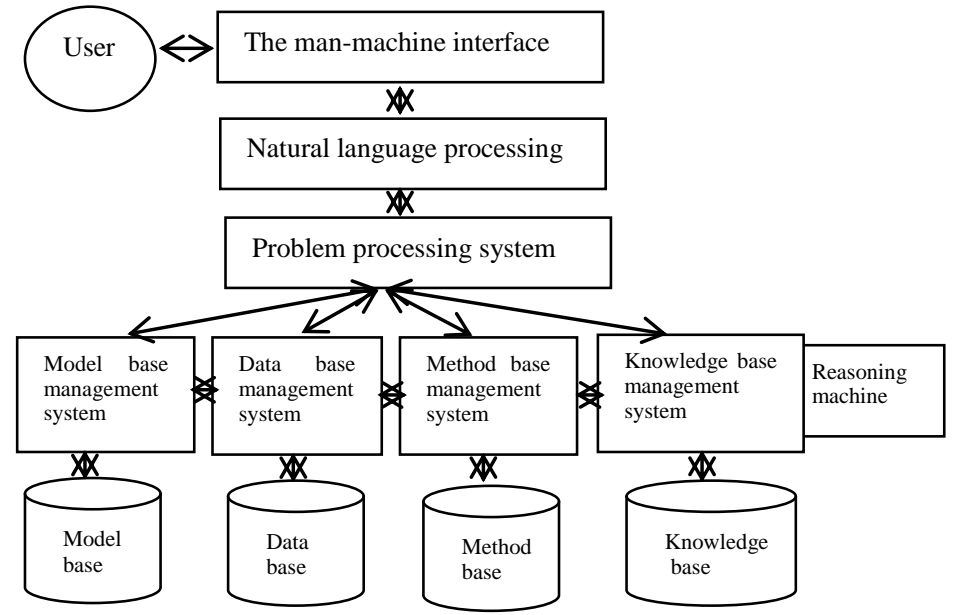

Fig. 3.IDSS structure

\section{The building of knowledge base and reasoning} machine

Knowledge base mainly store facts and knowledge of related problems, such as production rules, causality and experience, to enhance qualitative analysis ability of the system. Reasoning machine is similar to a knowledge processor that can match facts of problems in current tasks with domain knowledge in knowledge base to draw conclusions of problems. Knowledge reasoning is the core of artificial intelligence, by which computers gain problem-solving abilities of human experts to achieve function of decision support. Given the construction and management of knowledge base and reasoning machine is particularly complex, our research specially designs the development tools of HRM expert system, referred to as "ESBT-HR"(Expert system building tool for HR), and presents its technology roadmap to describe the building ideas of knowledge base and reasoning machine, as shown in Figure 4 (in next page).

\section{E. The building of model base and method base}

Model is the description of essential attributes of a system in some forms (such as the mathematical expressions and working process) to reveal the function, behavior and its change rule of the system. Model base is a program base composed by models and is one of the main characteristics in which DSS differs from other systems. Method base contains basic methods and standard algorithms, which support normal operation of models. In the DSS, model is similar to practical problems, while method is similar to basic algorithms, and models are composed by methods.

\section{1) The building of model base}

The comprehensive HRM model base mainly includes: (1) Markov model, Fuzzy synthetic evaluation model, Grey system model, Regression analysis model of HRM planning, Linear programming model; (2) Balanced scorecard model, Competency analysis model of performance management, and Correlation matrix model; 
(3) Modular arrangement predetermined time standards analysis model and Work factor analysis model of working methods; (4) Normal distribution model and Critical incident analysis model of job evaluation; (5) Hierarchy of needs analysis model, Double factor analysis model, Expectancy-valence theory, Psychological fair model of employee motivation; (6) Kirkpatrick model of training effectiveness analysis; (7) Horizontal development path model, dual career path model and behavioral career path model of career planning.

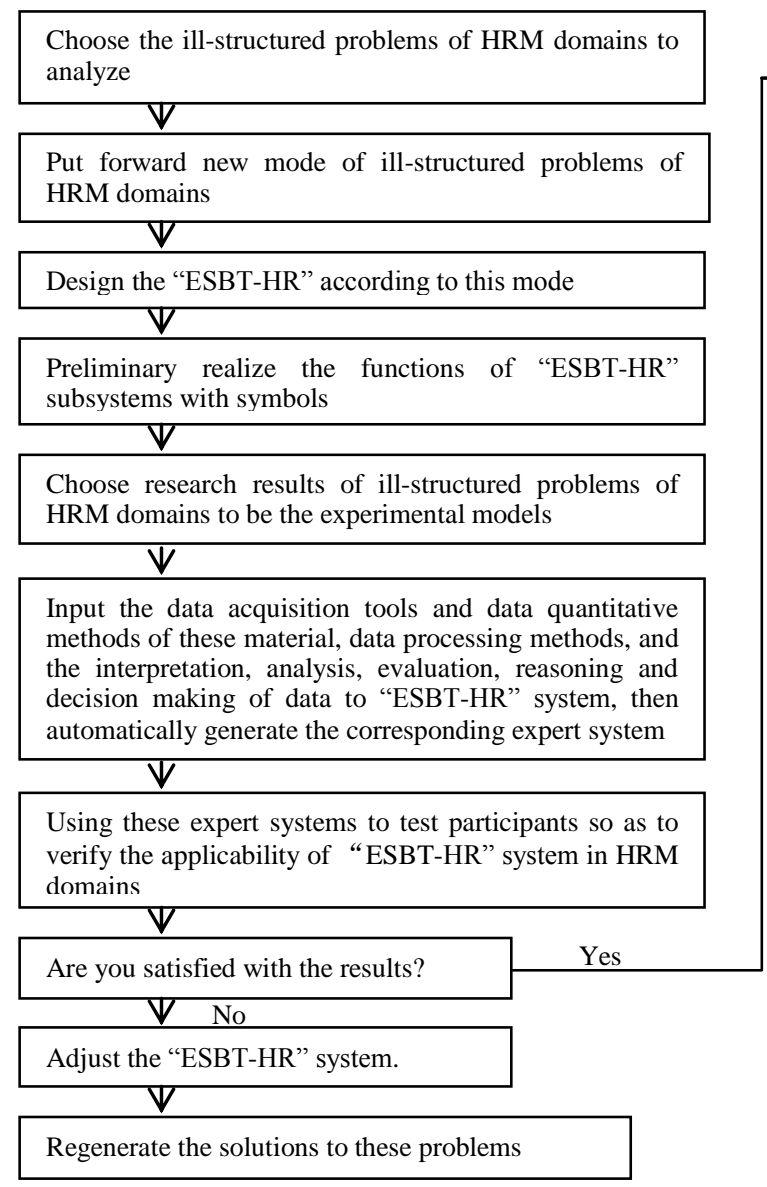

Fig. 4.The technology roadmap of "ESBT-HR" development

\section{THE BUILDING OF KNOWLEDGE-BASED COMPREHENSIVE DSS FOR HRM}

Based on the knowledge base, reasoning machine, model base and method base above, this research further builds the modules of HRM to form a comprehensive HRM overall solution. These modules include:

Organization and Job Management System. (1) Organization Management System, such as organization structure design, department responsibility management, human resource strategic planning, position establishment management, staffing management and the statistics of basic information of HRM; (2) Job Management System, such as job analysis questionnaire, job analysis survey form, job evaluation, work logs, detailed record of work days and competence model.

\section{2) The building of method base}

The method base includes numbers of common algorithms of HRM. Including: (1) common statistical methods; (2) experience estimation method, direct and indirect measurement of stopwatch measurement; (3) AHP and GEM of the determination of weight coefficients of performance management; (4) ranking method, taxonomy, factor comparison method and elements meter point method of job evaluation.

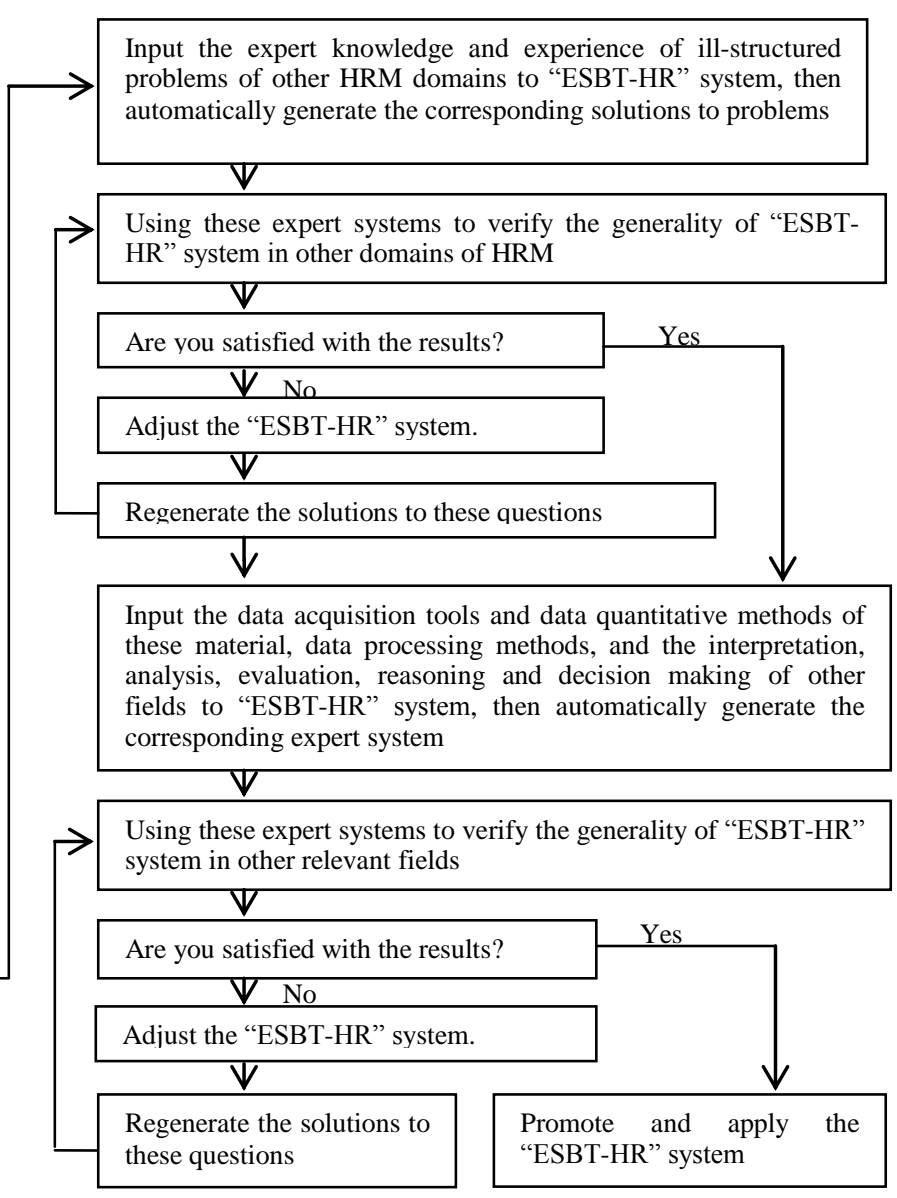

Human Resource Planning Management System. Including following modules: human resource strategic planning, personnel job arrangement plan, personnel supplement plan, personnel replacement and promotion plan, employee satisfaction survey and employee incentive plan, retirement and dismissal plan.

Recruitment Management System. (1) Recruitment Preparation System, such as department recruitment needs management and recruitment plan management; (2) Recruitment Implementation System, such as psychological test system(including Cattell 16 personality test, Temperament test, Hollander occupation interest test, Eysenck personality questionnaire, intelligence test and general aptitude test), LPC leadership effectiveness evaluation, assessment centers(including leaderless group discussion, in-basket test, case study, theme debate), 
interview management system(including general staff interview, structured interview, integrated management of interviews) and comprehensive evaluation of recruitment (including applicant qualification review, comprehensive evaluation of applicants)

Training Management System. Including following modules: training needs analysis, group discussions for training needs, information gathering for training needs analysis, training program management, training evaluation and integrated assessment of training system。

Performance Management System. Including following modules: assessment indicators management of departments and posts, enterprise strategy indicators management, reward and punishment records of employees, 360-degree assessment, assessment of simple ranking method, assessment of alternative ranking method, assessment of KPI, assessment of paired comparison method, assessment of the balanced scorecard, feedback of department assessment and employee performance evaluation.

Salary Management System. Including following modules: bonuses and allowances management, payroll deduction management, tax rate table management, basic data management of broad band salary, salary management of employees.

Career Management System. Including following modules: basic information analysis of employee, worksocial environment analysis, key issues analysis of employees; career questionnaire, employees' career planning management, employee assistance programs, backup talent management, cadre promotion planning.

Labor Relation Management System. Including following modules: labor contract management, renewal and change management of labor contract, termination management of labor contract, labor agreement management, leave management, personnel dispute management.

Human Resource Management Diagnostics. Including following modules: survey and analysis(S\&A) of HRM index, S\&A of enterprise cohesion and enterprise culture; S\&A of job satisfaction, S\&A of training results, S\&A of effectiveness recruitment, S\&A of effectiveness of salary and welfare management, S\&A of staff requirement, S\&A of performance management efficacy, S\&A of business condition, S\&A of labor relation condition.

Daily Management System. (1)Personnel File Management System; (2) Attendance Management System, such as employee vacation standard, fullattendance standard, employee vacation management and attendance management.

\section{APPLICATIONS}

\section{1) applications in business}

The IDSS of this research had been applied comprehensively in Guangdong backgammon electronics industry co., LTD, which has more than ten thousand employees and mainly four series of products: audiovisual products, communication products, education electronic products and life electric appliance. Because of the various products and distributed sales and services, the cloud-based model of HRM is especially necessary and important to the company. Our research system provides companies with comprehensive human resource management and decision making solutions, which is highly regarded by leaders and employees of the company.

2) applications in consulting services

The HRM Institute of our university not only undertakes the tasks of teaching and scientific research, but also provides enterprises and institutions with HRM consulting services. The institute has applied this research to a service platform and its present services are mainly as followed: (1) the selection and assessment of senior leaders in one state-owned enterprise; (2) the comprehensive personnel reform of one IRS; (3) the study of occupation crime prevention in one power grid; (4)The construction of Competency Model for senior leaders in one group company.

\section{3) applications in education}

The research achievement has also been applied to the experiment teaching based on Internet in one university. While instructing theories and methods, teachers can show students the specific operation of corresponding theories, systems, methods and research tools to make students grasp the knowledge in an easy way. What's more, students can also learn comprehensive HRM knowledge through internet anytime and everywhere, which not only greatly improve students' competency of solving problem, enhance their employment marketability, but also creates a new education mode for HRM in colleges and universities.

\section{FUTURE RESEARCH}

In this paper, we design a knowledge-based comprehensive DSS for HRM highlighting the importance of the knowledge base. Compare with previous studies, our HRM system is more comprehensive and professional. In the future research, we will continue to expand the content of expert knowledge, using more professional and richer expert experience to assist business decision-making; in the development of model base and method base, we will optimize the original algorithms, add new algorithms and introduce more advanced technology to integrate our IDSS to improve its effectiveness and professionalism.

\section{REFERENCES}

[1] Zhu Jing-yi, Distributed Resources Organization and Tasks Assignment Strategy for Cloud Computing[J]. Computer Measurement \& Control. Vol. 4, pp.1074-1076, 2013.

[2] Wu Zheng-yang, Research on the Cloud-based Human Research Management Sysytem Model[J]. China Computer \& Comminication. pp.162-163, August 2012.

[3] Tang Chu, and Zhou Guo-xiang, Resaerch on Decision Support System Based on SaaS Mode[J]. Computer Technology and Development. Vol.12, pp.1-5,2013.

[4] Zhang Li, Study on Human Resource Planning of Baotashan Company[D]. Management School, Xi'an University of Science and Technology. 2011. 